\title{
Motivation to transfer: linking perceived organizational support to training to personal goals
}

\author{
Isabelle Bosset • Etienne Bourgeois
}

(C) Springer Fachmedien Wiesbaden 2014

\begin{abstract}
The central issue we address concerns the conditions under which an employee participating in a training programme outside of the organization is likely to transfer his or her learning outcomes to the organization. More specifically, we will look at how some organizational factors (in particular perceived organizational support of training) may interact with certain individual factors (in particular employee's personal goals) in impacting the employee's motivation to transfer (Study 1 ), and how adults perceive their own motivation to transfer, and the possible impact of perceived organizational support on their motivation to transfer (Study 2). To this end, a first qualitative study (Study 1) was conducted with 20 adults at the University of Geneva and another qualitative study (Study 2) was conducted later on with another set of 18 adults, attending the same programme. Findings of Study 1 suggest that individual factors (personal goals) do interact with organizational factors (perceived organizational support of training). Thus, the effect of perceived organizational support of training is not mechanical, but seems to depend on the nature of the employee's personal goals. Findings of Study 2 give insight into learners' perceptions of motivation to transfer, and highlights some possible avenues for further investigation as interviewees indicate reasons (beyond personal goals) that keep them motivated to transfer. As a conclusion, Study 1 shows the relevance of studying the joint role of both individual and organizational factors in the motivation to transfer by raising awareness for this kind of interaction, and exploring possible ways those factors may interact, whereas Study 2 reports the interviewees' perceptions about motivation to transfer, as well as their views on how organizational support of training would affect their motivation.
\end{abstract}

This article is based on a doctoral dissertation by Isabelle Bosset at the University of Geneva.

\footnotetext{
I. Bosset $(\bowtie) \cdot$ E. Bourgeois

Section Sciences de l'Education, Universite de Genève

Boulevard du Pont d'Arve 40,

1211 Genèva 4, Switzerland

e-mail: Isabelle.Bosset@unige.ch
} 
Keywords Interaction between individual and organizational factors · Motivation to transfer - Perceived organizational support to training · Personal goals · Qualitative approach

\section{Transfermotivation: Verbindung zwischen einer Wahrnehmung der betrieblichen Unterstützung der Fortbildung und den persönlichen Zielen}

Zusammenfassung Die von uns angesprochene zentrale Fragestellung betrifft die Bedingungen, unter denen an Fortbildungsprogrammen außerhalb des Betriebes teilnehmende Mitarbeiter/innen ihre Lernergebnisse wahrscheinlich in den Betrieb übertragen. Im Einzelnen untersuchen wir, wie betriebliche Faktoren (insbesondere die wahrgenommene Unterstützung der Fortbildung durch den Betrieb) mit individuellen Faktoren zusammenwirken (insbesondere die persönlichen Ziele der Mitarbeiter/innen), um die Transfermotivation der Mitarbeiter/innen zu beeinflussen (Studie 1), und wie Erwachsene ihre eigene Transfermotivation und die mögliche Wirkung einer wahrgenommenen betrieblichen Unterstützung auf ihre Transfermotivation wahrnehmen (Studie 2). Zu diesem Zweck wurde eine erste qualitative Untersuchung mit 20 Erwachsenen an der Universität Genf durchgeführt (Studie 1), und später wurde eine weitere qualitative Untersuchung mit weiteren 18 am gleichen Programm teilnehmenden Erwachsenen durchgeführt (Studie 2). Die Ergebnisse aus Studie 1 weisen darauf hin, dass individuelle Faktoren (persönliche Ziele) tatsächlich mit betrieblichen Faktoren (Wahrnehmung der betrieblichen Unterstützung der Fortbildung) zusammenwirken. Demnach ist die Wirkung der wahrgenommenen betrieblichen Unterstützung der Fortbildung kein mechanischer Faktor, sondern sie hängt anscheinend von der Art der persönlichen Ziele der Mitarbeiter/ innen ab. Die Ergebnisse aus Studie 2 geben Einsicht in die Wahrnehmung der eigenen Transfermotivation und zeigen mögliche Ansätze für weitere Untersuchungen, da die Befragten auf weitere Gründe (außer persönlicher Ziele) hinweisen, die ihre Transfermotivation aufrechterhalten könnten. Fazit: Studie 1 zeigt die Relevanz einer Untersuchung der Zusammenwirkung persönlicher und betrieblicher Faktoren bei der Transfermotivation, indem sie das Bewusstsein für eine solche Interaktion stärkt und mögliche Interaktionsarten dieser Faktoren benennt, während Studie 2 die Wahrnehmung der eigenen Transfermotivation der Befragten und ihre Ansichten über die mögliche Wirkung einer betrieblichen Unterstützung der Fortbildung aufzeigt.

Schlüsselwörter Transfermotivation - Wahrgenommene Unterstützung der Fortbildung durch den Betrieb · Persönliche Ziele der Mitarbeiter/innen • Zusammenwirkung persönlicher und betrieblicher Faktoren · Qualitative Studie 


\section{Introduction}

It is not unusual that employees of an organization participate in "external" training, that is, delivered by external providers, outside of the organization. In such a case, the issue of transfer of learning back to the workplace becomes particularly relevant: to what extent does organizational support of training as perceived by the employee contribute to his or her motivation to transfer? For example, it could be intuitively hypothesized that the employee's motivation to transfer the learned skills back to the workplace will be enhanced by the fact that the decision to undertake the training programme has been agreed upon with supervisors in the first place, or else by the organization's positive attitude toward the ongoing training and its learning outcomes. More specifically, we will examine the impact of organizational support-as perceived by the employee - upon the employee's motivation to transfer. However, we suggest that this impact is not mechanical and could be affected by some individual characteristics, particularly learners' personal goals of training. We therefore make the following hypothesis:

The impact of the organizational support to training as perceived by the employee on his or her motivation to transfer depends on the nature of his or her personal goals, and in particular the importance given to training.

This hypothesis will be explored in the two qualitative studies presented here. Although the methodological design does not allow at this point for a systematic test of the hypothesis, those studies answer the following exploratory questions: do personal goals interfere with the effect of perceived organizational support to training? If so, what kind of personal goals would interfere? And in what way? How do interviewees speak about their own motivation to transfer? What is important to them?

\section{Theoretical background}

We have come a long way since Kirkpatrick's (1959) groundbreaking model defining learning as the sole antecedent of transfer of training. Since then, various authors have looked at the "transfer problem" (Baldwin and Ford 1988) by suggesting antecedents that fall into three categories: individual, pedagogical, and organizational (Ford and Weissbein 1997; Burke and Hutchins 2007; Blume et al. 2010; Colquitt et al. 2010). Our aim in this study is to explore possible interactions between individual and organizational antecedents of transfer. Thus, we look at perceived organizational support of training, personal goals of training, and motivation to transfer as a proximal variable of actual transfer. The reason perceived organizational support of training was used as the organizational variable in this study was because interviewees in a previous study (Bosset 2013) spontaneously mentioned this as an important issue during their training. 


\subsection{Organizational factors}

\subsubsection{Perceived organizational support (POS)}

Perceived organizational support theory focuses on the way employees perceive the support from their organization, that is, the extent to which the organization (1) values their contribution, and (2) cares about their well-being (Eisenberger 1986, 2002; Eisenberger et al. 2001; Eisenberger and Stinglhamber 2011). The theory further suggests that employees personify their organization and believe that it has either benevolent or malicious intentions towards them. The formation of POS is supposed to help satisfy socio-emotional needs, such as the need for approval, esteem, affiliation, or emotional support. The consequences of POS concern their subjective well-being, their orientation towards the organization and work, and their attitudes.

\subsubsection{Perceived organizational support (POS) and training-related issues}

Some authors (Pattie et al. 2006; Pajo et al. 2010; Madera et al. 2011; Cheng et al. 2012; Simosi 2012) have looked at the links between POS and various elements of training (such as transfer of learning, or perception of usefulness of the training). Other authors have tried to conceptualize perceived organizational support to training. For example, Hung and Wong (2007) conceptualised "Employee endorsement of CET - Continuing Education and Training" which takes two forms: on the one hand, a working climate that enhances learning, and on the other hand, rules and regulations that facilitate participation in training. Kraimer et al. (2010) introduce the "Organizational Support for Development" (OSD), which is defined as "the employees' perception that the organization provides programs and opportunities that support employee development" (p. 2). The antecedents include both participation to formal learning activities provided by the organization, as well as informal experiences that allow for the development of quality relationships with senior colleagues (career mentoring, for example). Kraimer and Wayne (2004) also developed the dimension of POScareer within the context of expatriate success. Koster et al. (2011) developed the "Perceived Support in Employee Development" (PSED), which is directly inspired by POS. It reflects an organization's investment in the general training of its employees. Their study shows that PSED is negatively correlated to intention to leave and mediates the relationship between participation in training and intention to leave. Finally, Lee and Bruvold (2003) define "Perceived Investment in Employee Development" as reflecting “employees' beliefs about the organization's commitment to improving their competence and enhancing their marketability, both internally and externally" (p. 983). Their study shows a direct link to affective organizational commitment and job satisfaction. Yet others (Maurer et al. 2002; Pidd 2004; Barnett and Bradely 2007) have looked into the combined effects of individual and organizational variables in order to understand the effect of POS, in the area of transfer of learning in particular. 


\subsubsection{Perceived organizational support to training (POS-T)}

We have used the concept of "perceived organizational support" as a basis for understanding perceived organizational support to training. We have kept two points that stand out from this theoretical background: (1) the antecedents that contribute to the perception of support, and (2) the aforementioned two dimensions of POS, namely, care for the employee's well-being and valuation of the employee's contribution. We justify this choice on the grounds that no theory of perceived organizational support of training exists.

1st dimension of POS-T: the perceived care for employees' well-being in the training

In our reformulation, care for well-being refers to the organization's logistical efforts with regard to the training. Logistical efforts refer to items such as financial support, time allowance, workload reduction, flexible working hours, and any other kind of arrangement provided by the organization that is meant to accommodate training. This dimension may also include all kinds of informal forms of encouragements for the training (not directly related to transfer, as this would be found in the second dimension of POS-T).

2nd dimension of POS-T: the perceived valuation of contribution resulting from training

This dimension refers to the employees' perception of the extent to which the organization acknowledges and values the contribution of their learning outcomes to the organization. We have looked through the literature on transfer of training in order to conceptualize this dimension. Organizational factors that support transfer of training (Baldwin and Ford 1988; Ford and Weissbein 1997; Burke and Hutchins 2007,2008 ) are found in relation to this dimension. We looked at six factors in particular, which all refer to the employee's standpoint:

1. Perceived strategic link (Lim and Johnson 2002; Montesino 2002). This concerns the employee's perception of the link between training and the objectives of the organization. Learning outcomes that are in keeping with the organization's objectives and strategies are more likely to be used, hence to be transferred to the workplace.

2. Perceived peer support (Chiaburu and Marinova 2005; Hawley and Barnard 2005; Chiaburu 2010), i.e., employee's perception that peers support the use of newly acquired skills in the workplace.

3. Perceived transfer climate (Rouiller and Goldstein 1993; Clarke 2002): a positive transfer climate includes cues to use new skills, consequences for correct use, remediation for not using skills, and social support (feedback and incentives).

4. Perceived opportunity to perform (Clarke 2002; Lim and Johnson 2002): unsurprisingly, this variable appears to be crucial in transfer of training. When there is no opportunity to use new skills, there is no possible transfer.

5. Perceived accountability (Kontoghiorghes 2002): this refers to the extent to which an organization expects the employee to use new skills. Beyond this form of "obligation", it gives the employee an important signal concerning the positive valuation and importance of the training. 
6. To complete this dimension, we also included Perceived Career Opportunity (PCO), defined by Kraimer et al. (2010) as: «employees' perceptions of the degree to which work assignments and job opportunities that match their career interests and goals are available within their current organization» (p. 4). In this context, we understood PCO here as career opportunities arising from and directly relating to training outcomes.

\subsection{Individual factors}

Whereas we hypothesize that perceived organizational support to training has an impact upon motivation to transfer, we do not however expect a "mechanical" effect of the former to the latter. As mentioned above, we suggest that the impact of perceived organizational support of training upon the individual's motivation to transfer may vary according to his or her personal goals related to training.

Carré (2001) proposed a typology of nine categories of (self-reported) motives of participation in training that are organized around two orthogonal dimensions (participation and learning). However, as Bourgeois and Chapelle (2006) suggest, whilst such typologies are useful to describe goals, they do not explain how they relate to one another, or how they are hierarchically organized. Carver and Scheier (1998) provide such a goal hierarchy model. So-called "be goals" (i.e., self-related goals) stand at the top of the hierarchy, whereas "do goals" (i.e., more concrete, pragmatically oriented goals) stand at the bottom. The authors further suggest that lower-level "do" goals are instrumental to the achievement of upper-level "be" goals. For example, aiming at acquiring new skills in a given training course (lower-level "do" goal) may serve as an means for getting a job promotion (higher level do goal), which in turn may contribute to improving one's self-image (upper-level "be" goal). In this perspective, along with Bourgeois (2009) and Kaddouri (2002, 2006, 2011), we assume a close link between self-related ("be") goals, personal goals of training, and, in fine, motivation to transfer ("do" goals). Valuation of the training and engagement in it will be high if training is perceived as a way to achieve "be" goals. As such, training may appear as a strategy to solve them. For example, a learner may view the HR MAS $^{1}$ training not only as a way to acquire new skills needed for the job, but also, by doing so, as a way to achieve the positively valued self as someone with an academic background. Conversely, ambivalence, and even resistance, would occur if training appears as incompatible with the individual's quest to achieve that aimed self (Higgins 1987).

Our sample consists mainly of individuals who entered training on a voluntary basis. Thus, one can expect a high level of engagement in the training, hence a high level of motivation to transfer. However, we raise the question of how perceived organizational support to training may alter motivation to transfer, as reported by the respondents ${ }^{2}$.

\subsection{Motivation to transfer}

Motivation to transfer is defined as: «the learner's intended efforts to utilize skills and knowledge learned in training setting to a real world work situation» (Noé and 
Schmitt 1986). Holton et al. (2000) define it as «the direction, intensity and persistence of effort toward utilizing in a work setting skills and knowledge learned» (cited by Devos and Dumay 2006, p. 183). Holton et al. (2000) include the enthusiasm at the idea to transfer and the perceived utility of the training. In 2002, Naquin and Holton developed the «Motivation To Improve Work through Learning» (MTIWL) construct that includes motivation to learn and motivation to transfer (Naquin and Holton 2002). Their study shows that MTIWL is the strongest variable that influences transfer. Lim and Johnson (2002) have also identified motivation to transfer as being a key variable in actual transfer.

Major transfer models of recent years have given an important role to motivation to transfer (Baldwin and Ford 1988; Cannon-Bowers et al. 1995; Holton 1996; Haccoun and Laroche 1999; Grossman and Salas 2011). In their 2009 literature review on the subject, Gegenfurtner et al. (2009b) argue that motivation to transfer is an essential step to ensure transfer. In 2009 these authors suggested to distinguish two dimensions in the concept of motivation to transfer, namely, autonomous motivation and controlled motivation. The former «can be defined as an internalized desire to transfer learning that is initiated and governed by the self (i.e., regulated by identification or by integration with one's values)» (p. 126). The latter «can be defined as a desire to transfer learning that is not initiated and governed by the self (i.e. regulated by external rewards or sanctions)» (p. 126).

Various studies show a significant relationship between motivation to transfer and actual transfer (Axtell et al. 1997; Lim and Johnson 2002; Devos and Dumay 2006; Burke and Hutchins 2007; Scaduto et al. 2008; Blume et al. 2010). Some authors (Kontoghiorghes 2002; Machin and Fogarty 2004) have looked at what influences motivation to transfer. Their results show significant effects of self-efficacy and motivation to learn. Holton (1996) identified four categories of factors influencing motivation to transfer: (1) Intervention fulfilment, (2) Learning outcomes, (3) Job attitudes, and (4) Expected Utility or Payoff. To our best knowledge, no study has looked at the effect of personal goals and expectations about training. These are important as they will provide grounds for the value attributed to training and thereby, for the motivation to transfer (Boudrenghien 2011). Without value given to training in relation to one's important personal goals, one can hardly expect motivation to transfer, especially the autonomous type. Thus, the study of personal goals attached to training and their potential role in the effect of perceived organizational support of training on motivation to transfer seems crucial.

\section{Research objectives}

The literature on transfer of training has shown that organizational support to training is a crucial factor of transfer. However, we assume that the positive effect of such support is not immune to individual factors, more specifically to personal goals about training. The two qualitative studies presented here explore this working hypothesis in various ways, both through semi-structured interviews. Although, given their methodological design, they are not supposed to strictly test any causal hypotheses, they yet provide quite interesting hints, which on the whole are in keeping with this hypothesis. 
In Study 1, we explore the interviewees' personal goals with respect to their training, their motivation to transfer and their perception of the support provided by their organization to their training (as well as their «sensitivity» to that issue). On that basis, we then infer prevailing patterns of interactions among these variables.

Study 2 partly replicates Study 1 (2 years later) with another sample of students attending the same programmes), but we push this phenomenological approach a little further. We first explore the interviewees' own perception and understanding of their motivation to transfer. Then we investigate the interviewees' own perception of the relation between their motivation to transfer and their organizational work environment, in particular in terms of organizational support to training.

\section{Study 1}

\subsection{Methodology}

Both studies presented here are qualitative in nature and closest to what Creswell (2007) identifies as phenomenological research. They are based on semi-structured interviews.

\subsubsection{Sample}

20 adult students ( 15 women and 5 men) enrolled in two continuing education programmes at the University of Geneva in the area of Human Resources (called "HR MAS" and "HR Certificate" see next section) were interviewed. The majority of them held middle to top management positions, whereas a minority were novices in this field. Some of them were interviewed in the middle of their training, while others were about to complete it. All respondents were working either full time or part time in a relevant HR field (Table 1).

\subsubsection{Training programmes}

The two programmes attended by the interviewees are the HR Certificate ("Certificate in Advanced Studies") and the HR MAS ("Master of Advanced Studies"). Both programmes are part of the continuing education provision of the University of Geneva.

The MAS consists of 60 ECTS credits and runs from January to December of the next year (23 months). It addresses HR managers, operations managers, and consultants or managers from other areas wanting to specialize in HR. It consists of 17 modules of 2.5 days each, along with a thesis. Admission to the programme, requires a Master's degree or equivalent, and at least 2 years of job experience in the chosen specialisation (three specializations are offered).

The Certificate consists of 20 ECTS credits and runs from October to June of the following year (9 months). It is aimed at HR managers and operations managers. It consists of 10 modules of 2.5 days each. Admission requirements are the same as for the MAS. Both programmes deliver academic content, with a strong emphasis on theoretical knowledge (as opposed to other existing more vocationally-oriented HR programs). 
Table 1 Sample Study 1

\begin{tabular}{|c|c|c|c|c|}
\hline $\begin{array}{l}\text { Interview } \\
\text { no. }\end{array}$ & $\begin{array}{l}\text { Sex and } \\
\text { age bracket }\end{array}$ & Training & Position & Job sector \\
\hline 1 & F, 20's & HR MAS & $\begin{array}{l}\text { Scientific Assistant 50\% and } \\
\text { HR Assistant RH } 20 \%\end{array}$ & University and Finance \\
\hline 2 & F, 30's & HR Certificate & HR Manager & Automobile \\
\hline 3 & F, 50's & HR Certificate & $\begin{array}{l}\text { Director of Nursing, and } \\
\text { Management Responsibilities }\end{array}$ & Hospital \\
\hline 4 & F, 30’s & HR Certificate & HR Manager & Transport \\
\hline 5 & F, 40's & HR Certificate & HR Business Partner & Food \\
\hline 6 & F, 30’s & HR Certificate & HR Manager & University \\
\hline 7 & F, 30's & HR Certificate & HR Manager & Transport \\
\hline 8 & F, 40's & HR Certificate & $\begin{array}{l}\text { Executive Assistant with } \\
\text { some HR Responsibilities }\end{array}$ & Education \\
\hline 9 & F, 20’s & HR Certificate & HR Assistant Manager & Police \\
\hline 10 & F, 30’s & HR MAS & Executive Director & University \\
\hline 11 & F, 50’s & HR MAS & HR Manager & Private Banking \\
\hline 12 & M, 50's & HR MAS & Consultant & Training and HR \\
\hline 13 & M, 40’s & HR MAS & Director of Quality & Pharmaceutics \\
\hline 14 & F, 40's & HR MAS & HR Manager & Hotel Business \\
\hline 15 & F, 40's & HR MAS & $\begin{array}{l}\text { Administration and Finance } \\
\text { Director, Landscape Archi- } \\
\text { tect, and Nurse }\end{array}$ & Construction Hospital \\
\hline 16 & F, 20’s & HR MAS & HR Assistant & Hotel Business \\
\hline 17 & F, 30's & HR MAS & Psychologist & Professional Orientation \\
\hline 18 & M, 30's & HR MAS & Office Manager & Law \\
\hline 19 & M, 40’s & HR Certificate & HR Manager & Watches \\
\hline 20 & M, 50's & HR Certificate & HR Manager & Machinery \\
\hline
\end{tabular}

Total F: 15 Total HR Certificate: 10

Total M: 5 Total HR MAS: 10

\subsubsection{Interview guide}

The interview guide was very open and consisted of questions relating to individual and organizational factors, as well as motivation to transfer. In the course of the interview, more questions were spontaneously asked to obtain further clarification or to enable the interviewee to elaborate further. The duration of the interviews was approximately $75 \mathrm{~min}$ (Table 2).

\subsubsection{Analysis}

The analysis was conducted following Creswell's (2007, p. 150) data analysis "spiral". First, interviews were transcribed verbatim and read several times in order to get an overall sense of the interviews. Then, we identified recurrent themes that appeared in all interviews, as well as sub-themes. For example, one theme was "Peer support" (a dimension of organizational support). Sub-themes of "Peer support" were: solidarity, informal support, admiration, no reactions, surprise etc. In total, we identified 15 themes. Only five of them were relevant to our research question. This is due to the fact that the questions in our guide were very open and thus interviewees spontane- 
Table 2 Interview guide Study 1

\begin{tabular}{|c|c|}
\hline Type of variable & Main questions \\
\hline Individual & $\begin{array}{l}\text { Can you tell me about the circumstances } \\
\text { you were in when you decided to under- } \\
\text { take this training? }\end{array}$ \\
\hline Individual & $\begin{array}{l}\text { How is this training important for you? } \\
\text { What do you expect from it? }\end{array}$ \\
\hline Individual & $\begin{array}{l}\text { What kind of HR do you wish to } \\
\text { become? Is this training helping you to } \\
\text { get there? }\end{array}$ \\
\hline Organizational & $\begin{array}{l}\text { Can you tell me what happened with } \\
\text { your organization when you announced } \\
\text { your project to undertake this training? } \\
\text { How did the project find its place within } \\
\text { the organization? }\end{array}$ \\
\hline Organizational & $\begin{array}{l}\text { Now that the training is underway, can } \\
\text { you tell me about how things are going, } \\
\text { between your organization and your } \\
\text { training? }\end{array}$ \\
\hline
\end{tabular}

Organizational Do you think that the organization sees a link between your training and its organizational objectives? Is this important to you?

Organizational How did or do your colleagues react to your training? How do you feel about that?

Organizational Regarding your last module, do you feel like you are authorized, or perhaps encouraged, to apply new skills?

Aim of the question

Find out about the meaning the training takes in the person's self-concept dynamic

Find out about personal goals of training

Find out about self-guides and possible discrepancies

Find out about POS-T before the actual training started: first reactions, logistics, encouragement etc. Here we expect to find elements pertaining to both dimensions of POS-T, with an emphasis on the 1st dimension (well-being)

Find out about POS-T whilst the training is going on. Here we expect to find elements pertaining to both dimensions of POS-T (well-being and valuation of training)

Find out more specifically about strategic link. This pertains to the 2 nd dimension of POS-T

Find out more about peer support. This pertains to the 2 nd dimension of POS-T

Find out more about transfer climate and opportunity to perform. This pertains to the 2 nd dimension of POS- $\mathrm{T}^{\mathrm{b}}$

Organizational/ Do you feel that the organization expects motivation to you to apply new skills from the traintransfer ing? How do you feel about that? What is your position on that? As things are today, do you wish to apply your newly acquired skills?

Organizational/ How do you see what will happen once motivation to your training is over? Do you talk about transfer this with your supervisor/organization? How do you feel about contributing your new skills to this organization in the future?

Motivation to I come back to your desire (or not) to transfer transfer your new skills to this organization. Can you tell me more about that?

Motivation to Has being supported (or not, or partially) transfer and im- affected you? Do you feel that the fact pact of POS-T that you've been supported (or not, or Find out more about accountability (2nd dimension of POS-T), and motivation to transfer

Find out more about PCO (Perceived Career Opportunity) (2nd dimension of POS-T), and motivation to transfer

Find out more about their motivation to transfer

Find out about possible impact of POS$\mathrm{T}$, in particular, on motivation to transfer partially) by your organization in your effort to train has an impact on that desire to use your skills?

${ }^{\text {an }}$ this section, interviewees talked primarily about their supervisors. Supervisor support was not included in the theoretical framework but was taken into account in the analysis.

bIn the interviews, it was difficult to disentangle transfer climate from opportunity to perform. This is the reason why there is one main question for both constructs. 
ously talked about themes that were irrelevant to the study. For example, the benefits of the training, or the support received from their families. Also, we combined themes that seemed to pertain to the same idea. For example, all items relevant to POS-T's 1st dimension were grouped together. Secondly, we reviewed the themes in the light of the literature review. Finally, we analyzed each interview on its own to come up with a summary highlighting the internal logic and prevailing interaction pattern between organizational and individual factors. We then came up with four profiles that share common orientations in terms of goals attached to training, and role of perceived organizational support.

All analyses were done by the first author and supervised and discussed with by Author 2. No software was used in this analysis.

\subsection{Findings}

The aim of Study 1 was to explore the possible role of personal goals about training in the impact of perceived organizational support upon motivation to transfer.

The analysis of the interviews enabled us to highlight four different prevailing patterns of interactions between organizational and individual factors, which represent four different learners' profiles ${ }^{3}$. These patterns reflect common characteristics pertaining to personal goals, and the role of perceived organizational support on motivation to transfer.

\section{Profile 1: Centrifugal (4 persons/20)}

The term "centrifugal" refers to the nature of learners' goals that tend to drive learners away from the organization, rather than move them closer. The interviewees belonging to the first profile are characterized by personal goals that are not linked to the organization, such as lifestyle (participating in training is seen as a kind of "hobby"), networking, or a strong desire to learn. Perceived organizational support varies from high perception of support, to low perception of support.

In this profile, perceived organizational training (POS-T) seems to have no effect at all on motivation to transfer, whether POS-T is perceived as high or low. In some cases, POS-T seems to be not even considered at the outset of training by the trainees, who deliberately do not engage in discussions with their management about a possible support to their training. No aspect of training is discussed, be it relating to logistical aspects (financing, for example) or to a possible contribution by the trainee, through newly acquired skills, to the organization. Trainees in this profile seem insensitive to POS-T; one could argue that their expectations of support are almost non-existent. They seem to be self-starters, determined to undergo their chosen training for the sole purpose of fulfilling personal goals not related to the organization. However, their motivation to transfer may still be high: In this case, others reasons interfere with the desire to use the skills at the workplace (such as image of oneself as a good professional, or increased work comfort through new skills).

Two variants could be drawn from our findings. However, due to the lack of enthusiasm from these learners when it comes to POS-T, it was difficult to clearly separate those who benefited from high POS-T from those who received low POS-T. 


\section{Interview excerpts Profile 1}

Goals not related to the organization:

There is also a kind of trend for training but for me it's not about "I need this training to do this job» but it's about pleasure to learn/Interview 15, p. 9

In fact it is a personal interest and in this particular training it is not the first time that I do this I am an insatiable curious and if I don't spend at least $20 \%$ of my time in training I get bored so yes I fell upon this training by chance/Interview 12, p. 1

Motivation to transfer:

I think it is a shame to send people to a training, rather on holidays, when it brings nothing, they might as well give them a holiday/Interview 1, p. 4

It bothers me to have to explain, again, and say "oh you know this is what I have learnt in my training », so I don't say it that way but I do implement things for my work/Interview 15, p. 10

Low sensitivity to POS-T:

I don't think in those terms (POS-T), if I want to do a training I shall do it and then I make sure I do what I must do in the time I have left/Interview 15, p. 5

- (Interviewer) Is it (POS-T) important to you?

- Maybe not so much, it (the training) is something that I have always wanted to do, it's a personal project/Interview 1, p. 3

\section{Profile 2: Uncertain (8 persons/20)}

The category refers to an uncertainty in the learners' training goals. These goals include the organization but also other elements, pertaining to the individual's more personal goals. By extension, uncertainty is also present in motivation to transfer. As goals are uncertain, so is the learners' motivation to transfer.

Goals may concern a desire to improve one's working environment (this would be a goal that includes the organization) and a strong desire to develop oneself and to gain a diploma for the sake of having a diploma. External mobility (considering a future position outside of the organization) is often a goal that excludes the current employer. Thus, their goals are more loosely linked to the organization and appear more volatile.

In this profile, POS-T does have an effect on motivation to transfer depending on its intensity. In other words, POS-T does make a difference in this case and learners seem particularly sensitive to the way the organization reacts to their training (aspects of well-being and valuation of contribution related to training).

Three variants were observed: 
(1) Variant 1: POS-T is high. In this case, motivation to transfer goes from uncertain to high. The learner is thus motivated, despite an initial uncertainty, to reinvest his or her newly acquired skills, in the organization.

(2) Variant 2: POS-T is low. In this case, motivation to transfer goes from uncertain to low. POS-T is unable to make up for the uncertain motivation related to uncertain training goals.

(3) Variant 3: POS-T is ambivalent. This means that POS-T may include some elements pertaining to well-being, such as financing, but exclude others, pertaining to valuation of contribution, such as extra help to apply the new skills to the workplace. In this case, learners seem to remain in state of uncertainty, and often "wait and see" what the organization's next move may be. This variant is thus characterized by a state of prolonged uncertainty and tensions, as the learner waits for a favourable outcome.

\section{Interview excerpts Profile 2}

Uncertain goals

At the moment I don't have a very precise idea of what the training will bring/ Interview 18, p. 4

I take some time for myself to do something that interests me and it is great because it corresponds probably, well not probably, but it does correspond to my organization's expectations so it brings something, there is a very personal meaning and a professional meaning that are somewhat reconciled/Interview 13, p. 15

\section{Motivation to transfer}

I think there is one dimension which consists of making the person responsible for their training, but then there are times when I get frustrated because I think they make me do this training but in the end they don't use me in the best way possible/Interview 18, p. 6

I think that there would be lots to do, even if I have limited experience, but there are lots of things I find surprising, there would be quite a lot of things to do, but it is quite individual/Interview 10, p. 4

\section{Sensitivity to POS-T}

The fact that they told me that there was not time for that (the training) for me it showed that I should not put all my eggs in the work basket and that I had to do something for myself/Interview 14, p. 4

- It's not about finances, that to me is not so important, it's maybe more about I think

- (Interviewer) Recognition?

- About what the training could bring, or where it could lead us, yes, taking this into account in fact, and not... nobody gives a damn!/Interview 10, p. 9 


\section{Profile 3: Centripetal (6 persons/20)}

The term "centripetal" refers to the nature of learners' goals that tend to drive learners closer to the organization, rather than move them away. In this sense, this profile is the opposite of Profile 1 (centrifugal). It also refers to the learner's intention to use the newly acquired skills in their organization, as derived from their goals.

The interviewees belonging to the third profile are characterized by personal goals that are clearly and fully linked to the organization. Training goals include the desire to improve things at work, such as work processes, knowledge, performance, service to clients, team efficacy. Perceived organizational support varies from high to low perception of support.

In this profile, perceived organizational training (POS-T) seems to have no effect at all on motivation to transfer, as in Profile 1, whether POS-T is perceived as high or low. If POS-T is high, it is perceived as pleasant, however, it is not the factor that will make a difference. If POS-T is low, there are other factors, independent of training, that make up for it. It must be noted that learners of Profile 3 are generally those who feel comfortable in their organization, and thus benefit from a general sense of support that can be related to POS.

Two variants were observed:

(1) Variant 1: POS-T is high. In this case, motivation to transfer stays high.

(2) Variant 2: POS-T is low. In this case, motivation to transfer stays high.

POS-T seems to make no difference on motivation to transfer, Profile 3 learners seem insensitive to organizational efforts with regards to their training. Perhaps they expect no less than what they receive (Variant 1), or they get a sufficient level of generalized support to compensate for low POS-T (Variant 2).

\section{Interview excerpts Profile 3}

Goals related to the organization

It (the training) is about transferring what I have learnt to the organization, that's the finality, what counts is the well-being of the organization before my own wellbeing (...) everyone benefits from it, it's about moving forward/Interview 20, p. 14

I was missing some HR skills and I told him (her supervisor) that it would be a good thing if I could train myself, which she accepted readily/Interview 8, p. 1

\section{Motivation to transfer}

It (transfer) is important because stacking on piles of validation work that stay on the bottom of a drawer is no use, to see that my management realises that we can change things in a positive way, what has been done so far is good but we can do so much better/Interview 20, p. 6

I submit plenty of projects, and I am very happy about the dynamic it creates, for the future and for now with regard to certain files we are working on, that we see differently and it has given me more comfort/Interview 8, p. 5 


\section{Sensitivity to POS-T}

I take it upon myself, that's part of the deal, one can't, when the organization is behind you financially it's already something, so on my side there must be an engagement, I step up a gear for a period of time, what are 2 years on a lifetime, on a professional career?/Interview 11, p. 10

I don't speak about the training at work because I consider myself lucky to have very good conditions, so I won't bother everyone, that's the way I see it, to complain and to say oh my I had to work all weekend no that is not/Interview 19, p. 5

\section{Profile 4: Compulsory (2 persons/20)}

Two out of the 20 respondents in our sample were engaged in the training on a compulsory basis. The questions raised in this study may take yet another form. Contrary to the other participants, the compulsory training does not fit in these participants' personal goals. The goals are imposed from outside. As an hypothesis, one could argue that those trainees would be particularly sensitive to POS-T as a means of giving meaning to the training. In case of low POS-T, we would expect learners to withdraw from the training. In case of high POS-T, we would expect learners to find new meaning in the training and thus engage in it more fully (with effects upon motivation to transfer).

\section{Interview excerpts Profile 4}

Goals not related to personal self-dynamics

We are like some kind of pawns on the chessboard (...) because we are not given the choice whether to do this training or not, we are told that if we want to work as a psychologist specialized in orientation in this organization, we have to get the $M A S$ (...) otherwise it is out of the question that you should get a job here Interview 17, p. 4

It's my boss who, because I only had two and half years of practice, I didnt think about undertaking a training right away (...) I was still young in the organization and I didnt really think about getting a training

Interview 9, p. 2

\section{Motivation to transfer}

There is a discrepancy between the content of the MAS and the reflexion process we must do to succeed in the modules, and the reality which is really, in my personal situation, to secure an internship

Interview 17, p. 5

I think he (her boss) expected me to set up a million things and he does not realize that we are no Nestlé, we cannot do the same things as Nestle, we have limited means, and if we do change things there will be repercussions, changes in evaluation will have repercussions on training, on salary, and this is not easy, he does not realize Interview 9, p. 3 
Sensitivity to POS-T

(Interviewer) You told me that sometimes you would like to share your critical thinking?

Yes in fact when I do have a critical thinking it would be good to share it (laughs) but it does not work

Interview 17, p. 11

The problem is that we never take the time in our HR team to think about different aspects, we are always just doing, often under pressure, and in fact we never take the time to say, so you have studied this theme what measures could we put into place

Interview 9, p. 6

\subsection{Discussion}

Study 1 shows that organizational support of training does, in fact, interact with personal goals of training, and has an impact on motivation to transfer. In Profile 1 ("Centrifugal"), the nature of personal goals is such that POS-T seems to have no effect on motivation to transfer. This means that some trainees, depending on the goals they set for their training, are insensitive to POS-T. From an organizational point of view, this means that all efforts made by the organization to support employees in this profile would be vain. From the employees' point of view, this gives insight into how training is perceived today, and how training can play a role (e.g., learning viewed as a "lifestyle") that is not necessarily obvious (as would be the case, e.g., of acquiring new skills).

In Profile 2 ("Uncertain"), the nature of personal goals is such that POS-T has a possible strong impact on motivation to transfer. These employees seem very sensitive to POS-T, and POS-T has the possibility of turning a situation around, when a person would initially perhaps intend to leave and subsequently would choose to remain with the organization and be motivated to transfer. From an organizational perspective, this is good news in the sense that POS-T can be a lever to influence motivation to transfer. However, it would seem that even in those cases, POS-T would need to be carefully planned and managed in order to be effective and meet the employees' expectations. From the employees' point of view, this profile shows a certain attachment and expectation towards the organization. This could in turn inform us about organizational commitment, and intent to leave (not explored in this study).

In Profile 3 ("Centripetal"), like in Profile 1, we see that POS-T seems to have no effect. The reasons, however, are quite different. In Profile 3, motivation to transfer appears to be high and unrelated to POS-T. These employees find reasons beyond organizational support that are sufficient to remain motivated. In Study 2, some of these reasons are explored. From an organizational point of view, these are the "dream" employees that are self-starters and do not expect much from the organization. However, they are also the ones who seem to benefit from the most comfortable working situations in our sample. Thus, they seem to benefit from a generalized sense 
of support (POS) that enables them to cope with whatever POS-T (high or low) they receive. From the employee's point of view, it raises the question of organizational commitment and how it works in today's economy. How much are some employees willing to sacrifice, to give, and for what results?

Profile 4 ("Compulsory") has a different status from the other profiles as personal goals about training are not present from the start. One can hypothesize that personal goals may emerge during the training as the employee is in contact with the training content, trainers, and fellow participants. From an organizational point of view, the question of how to motivate employees to transfer in this case is crucial as personal goals must be developed during the training. Without personal goals attached to training, one can expect no motivation to learn, and thus no motivation to transfer. From the employee's point of view, the question is how to deal with the compulsory nature of the training, how to make sense of it, and what can be expected from the organization given the obligation to attend the training.

As we mentioned in the relevant footnote concerning the profiles, we would assume that learners could "move" from one profile to another. For example, employees who would start the training with goals not attached to the organization may become so enthralled by the training content, that they would decide to try to apply them the current organization. Conversely, employees with goals attached to the organization may discover, through networking for example, other organizations that would interest them and slowly detach themselves from the current organization (and thus increase their motivation to transfer elsewhere).

The sample of this study consists mainly of people who took the initiative to participate in the degree programme (except those of Profile 4). Thus, one could argue that the posited interaction could be different, i.e. that personal goals would drive their behaviour (motivation to transfer). However, we argue that whilst this may be true (a direct effect of personal goals upon motivation to transfer), the effect of perceived organizational support would still be dependent on the nature of personal goals.

\section{Study 2}

\subsection{Methodology}

\subsubsection{Sample}

Eighteen adults (13 women and 5 men) were interviewed using semi-structured interviews. As in Study 1, most of them held middle to top management positions. They were interviewed once at the beginning of their training (one to three modules into the programme). All respondents were working either full time or part time in a relevant HR field (Table 3).

\subsubsection{Programmes}

The programmes (MAS and CAS) are the same as described in Study 1. Respondents in Study 2 were enrolled in those programmes 6 years after those in Study 1. 
Table 3 Sample Study 2

\begin{tabular}{lllll}
\hline $\begin{array}{l}\text { Interview } \\
\text { no. }\end{array}$ & $\begin{array}{l}\text { Sex and } \\
\text { age bracket }\end{array}$ & Training & Position & Job sector \\
\hline 1 & F, 30's & HR CAS & Recruiter & Petrol business \\
2 & F, 20's & HR MAS & Psychologist and Counsellor & Professional orientation \\
3 & F, 30's & HR CAS & Campus Recruiter & Banking \\
4 & F, 30's & HR MAS & HR Consultant & Headhunting \\
5 & F, 30's & HR MAS & HR Manager & Education \\
6 & F, 50's & HR MAS & Director & Professional insertion \\
7 & F, 40's & HR MAS & HR Manager & Public administration \\
8 & M, 40's & HR CAS & HR Project Manager & Public administration \\
9 & M, 40's & HR CAS & HR Manager & Public administration \\
10 & M, 40's & HR MAS & Social Educator & Education \\
11 & F, 40's & HR MAS & HR Manager & Public administration \\
12 & M, 40's & HR CAS & HR Specialist & Public administration \\
13 & F, 30's & HR MAS & HR Consultant & Food and beverage \\
14 & F, 20's & HR MAS & HR Assistant & International organization \\
15 & F, 30's & HR MAS & HR Consultant & Headhunting \\
16 & F, 30's & HR MAS & HR Consultant & Pharmaceuticals \\
17 & F, 40's & HR MAS & HR Manager & Hospital \\
18 & M, 40's & HR MAS & Service Manger & International organization \\
\hline
\end{tabular}

Total F: 13 Total HR Certificate: 5

Total M: 5 Total HR MAS: 13

\subsubsection{Interview guide}

The interview guide of Study 2 consists of three parts, as in Study 1: individual factors, organizational factors, and motivation to transfer. Since Study 2 is part of a much larger study currently in progress, we do not show here all questions that were asked, but only the ones relevant to Study 2 .

\begin{tabular}{lll}
\hline Type of variable & Questions & Aim of the question \\
\hline Motivation to transfer & $\begin{array}{l}\text { How do you feel about using your } \\
\text { new skills in this organization? Do } \\
\text { you want to? }\end{array}$ & $\begin{array}{l}\text { Find out about motivation to } \\
\text { transfer }\end{array}$ \\
$\begin{array}{l}\text { Expected effects of organi- } \\
\text { zational support of training }\end{array}$ & $\begin{array}{l}\text { Would you say that the organi- } \\
\text { zational support that you have motivation to transfer }\end{array}$ & $\begin{array}{l}\text { Find out about perceived impact } \\
\text { received (or not, or partially) has an } \\
\text { impact on you, in any way? Does it }\end{array}$ \\
& $\begin{array}{l}\text { impact your motivation to use your } \\
\text { new skills? }\end{array}$ & \\
\hline
\end{tabular}

${ }^{a}$ Many other questions that were asked during the interview gave information on motivation to transfer. Other questions asked were similar to the ones in Study 1. 


\subsubsection{Analysis}

The analysis was done using NVivo software. First, the interviews were transcribed verbatim and coded using both an inductive and a deductive methodology. The categories ${ }^{4}$ that are of relevance here are: "Motivation to transfer" and "Expected effects of organizational support of training upon motivation to transfer". The category "Motivation to transfer" contains all references made by the learner in reference to his or her desire, enthusiasm, and intention, to apply the learnt skills to his or her workplace. The category "Expected effects of organizational support of training upon motivation to transfer" includes interviewee's response to the following question: "Would you say that POS-T has an impact on you, in any way?". The question was open enough for respondents to talk freely about POS-T. The question of motivation to transfer came up, in most cases, without the interviewer having to press for an answer. Secondly, once the coding was completed, both categories were analysed on their own to reflect the detailed content of each.

\subsection{Findings}

The aim of Study 2 was to explore (1) the interviewees' representations and feelings about their motivation to transfer and (2) their perception of the relationship between the support from their organizational environment and their motivation to transfer. Accordingly, findings are organized into two parts.

Part 1: All participants showed a high level of motivation as they began their training. They were all very keen to use their new skills in their current organization.

Each time I see something that can be done, I suggest it

Interview 16, ref5. 2

However, when going in more depth, the study highlighted the following points:

(1) The nature of what the trainees wish to transfer: Knowledge derived from the course, and informal knowledge derived from the contact with other professionals

During the course, I am a little biased because I always think about what I know first and then the link (to the organization) comes

Interview 1, ref. 1

(2) The necessity to transfer to give meaning to the effort made for the training: Transfer appears as the ultimate goal of training, and seems to give a meaning to the whole enterprise of attending a training program.

Continuing education, if you don't use it back at the workplace, I don't see why you do them

Interview 15 , ref. 4 
(3) The perceived difficulties to transfer (despite high motivation): The nature of the content of training, the lack of time back to work, the difficulty in evaluating transfer, the hierarchical status of the trainee, the organizational structure and decision-making procedures, the loneliness on the job, the type of management, and the reactions from the work environment

Regarding the nature of the content of training: The last two modules are more a personal reflexion than things that one can apply (to the workplace) directly, I think

Interview 1, ref. 1

Regarding the lack of time back to work: We have a lot of skills in our human ressources (...) all the people who have written a dissertation etc. but we do not share or we do not take the time for that

Interview 10, ref. 6

Regarding the difficulty in evaluating transfer: How do we implement (what's been learned), how do we measure it, how do we see a return on investment (...) I could see myself developing these points

Interview 10, ref. 5

Regarding the hierarchical status of the trainee: I have already shared an idea with me superior and like I said everything that is doable at my level my superior says "go for it" I can do it but then everything that is strategic or more no I can improve processes but I cannot improve strategies

Interview 16, ref. 3

Regarding the organizational structure and decision-making procedures: It (the course) will really be interesting for me but then one must remember that as a large organization, strategies are decided in Zürich and we only apply them so to make big changes in strategic terms, that will be rather difficult within our margin, but we can always apply small things

Interview 3, ref. 1

Regarding the loneliness on the job: The next appraisal work will be useful but it will be useful for me because I am the only one to do this job

Interview 3, ref. 2

Regarding the type of management: I think that this type of management, where there is no interest where there is no valuation is a type of management for me that is toxic I think this type of entrepreneurial management is not good for its people because it puts them in a position where they are not encouraged

Interview 6, ref. 3

Regarding the reactions from the work environment: I am motivated to transfer because also I didn't get slapped in the face when I suggested ideas I didn't get asked to go back to my studies telling me your theoretical ideas are good but here it's reality, that didn't happen so my motivation is still intact

Interview 8 , ref. 10 
(4) The process of transfer: For some, transfer appears automatically, almost by magic. For others, transfer requires a process.

I come back from a module and on Monday morning I use what I have learnt it's direct it's automatic

Interview 11, ref. 2

I will take some parts (of the appraisal work) and transform them in order to make a note for my superior andmy department for the implementation of certain proposals Interview 7 , ref. 7

(5) Transfer as a sine qua non condition of innovation: Change and innovation are perceived as being at the very heart of the transfer process.

To bring solutions or recommendations that are "out of the box" as the English say it means to take off the blinkers to look at things differently so that the solutions that one gives are more promising in terms of change Interview 18 , ref. 2

(6) Transfer is perceived as a personal initiative: For most learners, transfer is perceived as being their responsibility. Thus, one can argue that expectations of POS-T are low, at least at the beginning of the training.

It is up to me only to do it (transfer) or not to do it Interview 11 , ref. 4

Part 2: When asked about the extent to which POS-T affected their motivation to transfer, learners fell into three profiles: (1) Those who thought POS-T affected their motivation (in either a positive or a negative way), (2) those who thought it did not, (3) and those who were not sure about how POS-T would affect them. Their discourse gives a broader understanding of the reasons, beyond their goals related to training, that may make POS-T effective or not. In this sense, these findings give insight into what does actually motivate employees to transfer.

Profile 1: These learners expected POS-T to make a difference in their motivation to transfer. In positive terms, the reason they gave included was that POS-T triggers reflexion.

Yes of course to show it immediately, it's interesting "come on show us", I think that one has even more interest or motivation to speak about it or to look into it concretely, how can we do this internally and then to work with other colleagues and say "look at this aspect do you see the same thing as me"./Interview 12, ref. 2 
In negative terms, the reasons were: The absence of POS-T suppresses all potential sharing of knowledge; the absence POS-T is expected as there is little support in the organization, in general.

I use it but I use it for myself (...) it's more underground ${ }^{6}$ (...) if my boss asks me to produce a synthesis of the situation he doesn't care if I use (what I've learnt in the training) a simple thing like a SWOT analysis will be enough (...) because he does not care about the rest./Interview 17, ref. 1

Profile 2: These learners were adamant that POS-T would make no difference in their motivation to transfer. The reasons they gave include:

The hierarchical status of their job: When their status is high, learners consider it their duty to transfer. The question of POS-T is eluded.

It (POS-T) makes no difference because I am at a level where this is not the question/Interview 11, ref. 1

The perception of their mission: Learners consider transfer to be an integral part of their jobs, be POS-T provided or not.

There is something to do here that will benefit the organization (...) I'm going to do it (...) for me this is part of my mission (...)/Interview 9, ref. 1

Their personality: some learners say that nothing could stop them from using the new skills. They consider it to be part of their personality to attempt transfer no matter what.

This is part of my personality it (POS-T or lack thereof) will not hinder me (...) I constantly am full of ideas so this is not a problem./Interview 9, ref. 2

Their working environment: even without POS-T, some learners say they would use their otherwise stimulating work environment and its opportunities to ensure transfer. POS-T makes no difference.

We do it automatically we return the know how (...) or little hints to feed to think outside of the box because innovation is very encouraged in our organization./ Interview 13 , ref. 1

The automatic nature of transfer: for some learners, transfer seems to happen automatically, in any way. In this case, POS-T is not required and makes no difference.

I think it is a training that will train your spirit whether you want it or not then you go back to work and whether you want it or not your spirit will be trained so you see things differently./Interview 15, ref. 2 
Profile 3: These learners were not sure as to how POS-T would affect them. Some of them were waiting for POS-T to be confirmed (for example, they did not know if or when they would receive financial support, or how their supervisor would react to their training).

At the moment I'm in a little discomfort or uncertainty (...) it is true the role of the employer will have a strong impact but at the moment I'm observing/Interview 3, ref. 1

In this situation, learners may consider two options: either, to fully engage in the organization, in spite of lack of POS-T, or, to disengage and consider the training as their own (with goals thus not including the organization).

I think there are two scenarios either my propositions will be accepted and it is for the better because my organization will see a return on investment either they won't and I will become I will tip towards it is a CAS just for me/Interview 7, ref. 1

Study 2, part 1, reveals interviewees' perceptions about motivation to transfer and highlight: the importance of transfer in the goals attached to any training and in the innovation process inherent to organisations, the perception that transfer is one's own responsibility and relies on personal initiative, possible obstacles to transfer, and perceptions on the nature of the transfer process. Study 2, part 2, reveals three profiles in terms of how respondents value POS-T and its role in their motivation to transfer.

\subsection{Discussion}

What strikes us in the first part of Study 2 (points 2 and 6) is the fact that transfer is considered as the ultimate goal of training and that it is also seen as a personal initiative. Consequently, we can assume that employees' motivation to transfer is high in the first place, regardless of POS-T. This is "good news" for organizations, who can rely on autonomous motivation to transfer from their employees. From the latter's perspective, it shows how individuals today engage themselves personally beyond any instrumental consideration. We can therefore see here a strong link with personal goals. Engaging in training is not a trivial enterprise, but rather one that engages the learner entirely, up to the "last" step of training, which is transfer. The employees" preoccupation with innovation (Point 5) can be linked to this, as well as to autonomous motivation.

The observation that transfer is widely viewed as falling under one's initiative is perhaps not surprising when considering the longstanding and widely spread HR discourse on the individual's personal responsibility for their own training and employment (Carbery and Garavan 2005). Employees seem to have internalized that discourse on personal initiative and responsibility. Point 3 highlights the obstacles to transfer. Most elements reported by the interviewees concern the organization, although only "reactions of the work environment" refers specifically to POS-T. The other elements, such as lack of time, organizational structure and type of management, are seen as predominant. Higher hierarchical status is seen as a facilitating 
factor by certain interviewees, suggesting that those who are in higher position enjoy more freedom to use their new skills and implement new processes. Last but not least, it is surprising to see that some employees consider transfer to be automatic (Point 4), as if there were no difference between learning and transferring, or motivation to learn and motivation to transfer. This can be related to Point 1: automatic transfer may occur when employees talk about new attitudes acquired in training and a general culture (in this case, HR culture) rather than hard skills.

The second part of Study 2 looked at interviewees' perception of how POS-T would, or would not, affect them in terms of motivation to transfer. Interviewees who fell into Profile 1 explain why POS-T would affect them: the sharing of knowledge, and the reflexion it triggers, seems crucial. This can be related to the importance of feedback (Van den Bossche et al. 2010).

Learners in Profile 2 give valuable insight into why POS-T would not affect them, beyond their personal goals about training (either not linked at all or strongly linked to the organization, as in "Centrifugal" and "Centripetal" Profiles of Study 1). Most striking is the sense of "duty" and "mission" that is expressed here. This, again, can be linked to the idea of personal initiative and responsibility, but also, to personal "be" goals (what do I need to do to be a good professional). In this sense, not only one's engagement in a specific training programme that makes sense for the self, but also the actual transfer of training are an integral parts of this process. In other words, attending a training to regulate a self-discrepancy (Higgins 1987) only makes sense if the content of the training can ultimately be transferred. Those who say it is their personality that "forces" them to attempt transfer anyway can be linked to the "Centrifugal" Profile of Study 1, in the sense that they are self-starters, not relying on anyone or anything else to support transfer. It can also be linked to locus of control and feelings of self-efficacy, which are stable individual antecedents of transfer (Devos and Dumay 2006). Those who say that they would use their otherwise stimulating work environment to attempt transfer (despite low POS-T) can be linked to the "Centripetal" Profile, where we assumed that those were people who benefited from a supportive general work environment, saw specific support for training as unnecessary. Finally, the "automatic nature of transfer" reminds us of Part 1 of Study 2 where we already found this result.

Last but not least, the interviewees of Profile 3 remind us of the "Uncertain" Profile of Study 1. They are characterized by an attitude of "wait and see". Furthermore, they express the effect of POS-T in terms of how they consider the training. If POS-T is satisfactory, they will intend to transfer and contribute to the organization. If POS-T is unsatisfactory, they will consider the training as their own business, not the organization's (with consequences to be expected upon motivation to transfer). 


\section{Summary of findings}

\begin{tabular}{ll}
\hline Study & Main findings \\
\hline Study 1 & $\begin{array}{l}\text { Personal goals about training appear to play a significant role in the effect of perceived or- } \\
\text { ganizational support of training (POS-T) on motivation to transfer. In other words, the na- } \\
\text { ture of personal goals (either closely or more loosely linked to the organization) interferes } \\
\text { with the effect of POS-T: when personal goals hardly include the organization (Profile } \\
\text { "Centrifugal") and when they strongly do ("Profile Centripetal"), POS-T seems to make } \\
\text { no difference in the motivation to transfer. However, when personal goals are uncertain } \\
\text { (Profile "Uncertain"), POS-T can change motivation to transfer in either a positive (en- } \\
\text { hancing motivation) or negative (reducing motivation) way. The Profile "Compulsory" has } \\
\text { a special status as employees in this set did not freely choose participation in the training. } \\
\text { Thus, we can only hypothesize that in this fourth profile, strong POS-T would enhance } \\
\text { motivation to transfer, by giving the learner the chance to gradually find a meaning to their } \\
\text { training whilst it is going on. On the opposite, we would expect low motivation to transfer } \\
\text { (in particular, autonomous motivation) in case of low POS-T } \\
\text { When asked about motivation to transfer, interviewees reported the following percep- } \\
\text { tions: transfer is the ultimate goal of any training; transfer is one's personal initiative } \\
\text { and one's personal responsibility; innovation is at the heart of motivation to transfer; } \\
\text { obstacles to transfer are identified; transfer may be seen as automatic, or else as needing a } \\
\text { recontextualisation } \\
\text { When asked about if and how POS-T would affect their motivation to transfer, inter- } \\
\text { viewees fell into three profiles. In Profile 1, respondents said that POS-T would affect } \\
\text { them, as POS-T either triggers reflexion or hinders the sharing of knowledge. In Profile }\end{array}$ \\
2, respondents gave reasons, beyond personal goals, that would make them "immune" to \\
PoS-T. The reasons given include: high job status; a sense of "mission" to transfer; their \\
part 2 \\
personality; the otherwise supportive work environment; the automatic nature of transfer. \\
In Profile 3, respondents said they were not sure if and how POS-T would affect them. \\
They are characterized by "wait and see" attitude
\end{tabular}

\section{General discussion}

Our findings have both theoretical and practical implications. At a theoretical level, they are consistent with our initial hypothesis based on the transfer literature. We know today that individual, organizational and pedagogical antecedents influence transfer. However, no research that we know of has integrated both individual and perceived organizational factors and their possible interactions. Through this study we partly answer Devos and Dumay's (2006) call for more research exploring links of moderation and/or mediation between antecedents of transfer (with the reservation, of course, that a qualitative study of this nature is typically not generalizable and cannot show a stricto sensu "moderation" effect). The fact that this research is qualitative adds another insight in a literature widely dominated by quantitative models and research design. Most empirical work shows that organizational support of transfer benefits ultimate transfer, however, little is known about how various elements are perceived by the trainees, in other words, how they interpret what the organization offers them. This is why we have found it heuristically fruitful to look at how these elements are perceived through the lens of personal goals.

Furthermore, this study considers factors related to personal goals, in particular self-related goals (or "self-guides" as defined by Higgins 1987), which, as far as 
we know, have never been taken into account in theoretical models or in empirical research about transfer. Finally, this study raises the question of the relation between various factors: While this study suggests that individual factors conditions the effect of organizational factors, one can ask whether the opposite could be true as well.

We suggest two additional elements regarding our theoretical framework. Firstly, in Eisenberger's POS theory, training is considered as an antecedent to POS. We suggest that it is the actual support of training (POS-T) that may constitute an antecedent to POS, not just training itself. Furthermore, our study suggests that POS-T must be looked at in conjunction with personal goals of training. Secondly, and with reference to Kaddouri's concept of self-concept dynamics, we suggest to add a third type of "attitude to training". This author conceptualises two types of attitudes to training: One is autonomous, the other is externally supported. In the first case, there is a misfit between one's own training project, and another party's project for oneself. For example, this may happen when a person wants to undertake a training, but the employer is clearly against it. In the second case, the training project is supported by the employer. However, in the "uncertain" profile, the project is not as clearly defined. Both sides (the learner and the organization) seem uncertain about what direction is to be given to the training. Thus, we suggest an "uncertain" attitude to training.

On a practical level, our study highlights the necessity to take into account what is at stake for both the employee and the organization in this kind of training. From the learner's point of view, and this is especially true in Profile 2 of Study 1, it shows the complexity of the relationship between training and organization, and the ambivalences that can result from it. As a matter of fact, organizational support of training is not perceived in the same way throughout the population. From the organization's point of view, it appears that it is not enough to support the trainee in his or her training without taking his personal goals into account. Whereas there seem to be a lot of cases when the organization can make a difference, and thus expect a "return on investment" (especially in those many cases when the training is actually funded by the organization), it clearly appears that each case is different and that individual factors do play a crucial role. From the training point of view, our research questions the actual training system and how it can better support trainees in their negotiations regarding their training and the importance of the training in the organization.

The results from the two studies can be linked in various ways. Firstly, Study 2, part 2, extends Study 1 in the sense that it goes beyond personal goals of training to reveal further reasons why one might be motivated to transfer, or not. Secondly, Study 2, part 2, confirms that there are various profiles in terms of adult learners and their expectations of support of training. In this sense too, Study 2 part 2 extends Study 1 and seems to confirm this main finding. Thirdly, Study 2, part 1, by giving voice to one of the main stakeholders in training, namely the trainees themselves, offers valuable insight into the reasons that may help to explain why motivation to transfer may be maintained, even when POS-T is low. Allover, both studies provide converging evidence for the interaction of motivation to transfer and POS-T: while Study 1 is limited to the role of personal goals, Study 2 partly overcomes these constraints as it gives more insight into the reasons behind motivation to transfer and the ways that learners themselves value POS-T or not. 


\section{Research limitations}

First, all data are self-reported. If this is in keeping with our methodology, it limits our results as all organizational data are about perceptions. Second, the issue of time was not taken into account, while one could argue that all profiles are dynamic. Thus, our study does not reflect changes of POS-T, goals, and/or motivation to transfer over time. Third, the type of organization each participant belongs to has not been taken into account. It is however reasonable to think that organizational structure and culture influences perception of support, goals of training, and motivation to transfer. Fourthly, the solely qualitative nature of the studies limits the scope of our findings, which of course cannot be considered as generalizable. Fifthly, one can raise the question as to how organizational support of training may affect trainees in different training situations, such as internal trainings, or workplace training. Our sample provides solely from people engaged in an external, long, and academic training. These characteristics do not allow for any generalization. Sixthly, our sample primarily included participants that entered training on a voluntary basis and might therefore attribute high importance to training in their goals. This results in low variation of the "personal goals "variable. Including participants who participated on a mandatory basis would give more variety.

\section{Future research}

"Protean career attitude" (Hall 2004) and "boundariless career attitude" (Briscoe and Hall 2006) may give insight into how people perceive their careers, and thus give further explanation regarding learners in Profile 1 (centrifugal). The question of organizational identification, but also professional identification (in this study, to the HR community) is another avenue that one could look at to better understand motives in transfer of training.

What exactly is meant by POS-T, which elements it encompasses, and how it affects trainees in terms of their expectations of support, is another possible avenue for research. In this light, POS-T does not exist as such but is a function of learners' needs and/or expectations with regard to organizational practices that support their training. A recent study explores the meaning given to supervisor support, by the employees themselves (Lancaster et al. 2012).

The link between study 1 and study 2 is promising in the sense that by asking trainees about motivation to transfer, we have direct access to their thought processes and gain qualitative insight into motivation to transfer. New questions are being raised. For example, the issues relating to high job status and motivation to transfer asks whose responsibility it is, ultimately, to transfer. When learners mention their personality or the idea of "mission" as antecedents to motivation to transfer, one wonders about the importance of dispositional factors (rather than situational) in the study of motivation to transfer. Regarding innovation and change, and organizational structures that support those, one can wonder whether they encompass POS-T and constitute a generalized support system. In other words, do we need POS-T for specific 
training actions, or do we need organizations that support change and innovation whatever the source of those can be?

We were surprised to see that many learners said they would not be affected by lack of POS-T. In this sense, study 1 should be reassuring for organizations as learners seem to find enough reasons, within themselves or the organizational environment, to ensure motivation to transfer. How do learners cope with lack of support and what strategies do they fall back onto to ensure a sufficient amount of sense in the process of a long training? Sense making theory (Weick 1995; Weick et al. 2005) may come in handy to better understand this, as might research on psychological contracts and their possible breach (Chaudhry et al. 2009)

Finally, study 2 gives insight into how some learners would react when POS-T is not present. The "underground" motivation to transfer was found in more than one person. This gives a new qualitative description of motivation to transfer: One can be motivated to transfer, however, the scope of the actual transfer is limited either to one's own comfort, or to close and supporting team members. What does that mean for organizations that value knowledge sharing and depend on innovative and up to date skills in order to stay competitive?

Acknowledgements Both articles presented here are part of a doctoral dissertation underway at the University of Geneva, Switzerland.

A special thank you to the interviewees who are working full time and studying. We appreciate you giving us some of your precious time.

\section{Endnotes}

1 HR MAS: Master of Advanced Studies in the field of Human Ressources.

2 It should be noted that this study is not longitudinal. Changes in the motivation to transfer as a result of perceived organizational support were therefore attended to only through respondents' self-reports (retrospective accounts) at a given point in time.

3 NB: The profiles are not considered as being stable: They only reflect a moment in time and further investigation is necessary to determine their possible change over time. Changes would include goals and perception of organizational support of training.

4 By category we refer to the name of the «node» used on NVivo software. A category also refers to our theoretical background.

5 The number refers to the interview excerpt as listed in NVivo's categories.

6 By «underground», this interviewee means that whilst she is motivated to transfer, the scope of her actual actions remain limited.

7 CAS: Certificate of Advanced Studies (see Programmes under the Methodology section).

8 We have freely translated the French «rapport à la formation» by « attitude to training».

9 For a description of what is meant by «underground motivation» (as stated by one interviewee), please refer to page 20 .

\section{References}

Axtell, C. M., Maitlis, S., \& Yearta, S. K. (1997). Predicting immediate and longer-term transfer of training. Personnel Review, 26(3), 201-213. 
Baldwin, T. T., \& Ford, J. K. (1988). Transfer of training: A review and directions for future research. Personnel Psychology, 41, 63-105.

Barnett, B., \& Bradely, L. (2007). The impact of organisational support for career development on career satisfaction. The Career Development International, 12(7), 617-636.

Blume, B. D., Ford, K. J., Baldwin, T. T., \& Huang, J. L. (2010). Transfer of training: A meta-analytic review. Journal of Management, 34(4), 1065-1105.

Bosset, I. A. (2013). Le rapport à l'apprentissage en formation continue. Résultats d'une étude de cas d'une formation de formateurs de l'Université de Genève. In I. Bosset, A. Girardin, S. Jaquement, \& L. Türkal (Ed.), Confrontations de l'adulte en formation continue: la formation des formateurs d'adultes à l'Université de Genève (Cahiers de la Section des sciences de l'éducation. Pratiques et théorie, 133, p. 15-55). Genève: Université de Genève, Faculté de psychologie et des sciences de l'éducation.

Boudrenghien, G. (2011). Elèves aujourd'hui... Et demain? Etude des antécédents et des conséquences de l'engagement envers un but de formation. Doctoral thesis in Psychological and Educational Sciences, Université catholique de Louvain.

Bourgeois, E. (2009). Apprentissage et transformation du sujet en formation. In J. -M.Barbier, E. Bourgeois, G. Chapelle, \& J. C. Ruano-Borbalan (Eds.), Encyclopédie de la formation (pp. 31-69). Paris: PUF.

Bourgeois, E., \& Chapelle, G. (2006). Apprendre et faire apprendre. Paris: PUF.

Briscoe, J. P., \& Hall, D. T. (2006) The interplace of boundaryless and protean careers: Combinations and implications. Journal of Vocational Behavior, 69, 4-18.

Burke, L. A., \& Hutchins, H. M. (2007). Training transfer: An integrative literature review. Human Resource Development Review, 6(3), 263-296.

Burke, L. A., \& Hutchins, H. M. (2008). A study of best practices in training transfer and proposed model of transfer. Human Resource Development Quarterly, 19(2), 107-128.

Cannon-Bowers, A., Salas, E., Tannenbaum, S. I., \& Mathieu, J. E. (1995). Toward theoretically based principles of training effectiveness: A model and initial empirical investigation. Military Psychology, $7(3), 141-164$.

Carbery, R., \& Garavan, T. N. (2005). Organisational restructuring and downsizing: Issues related to learning, training and employability of survivors. Journal of European Industrial Training, 29(6), $488-508$.

Carré, Ph. (2001). De la motivation à la formation. Paris: L'Harmattan.

Carver, C. S., \& Scheier, M. F. (1998). On the self-regulation of behavior. Cambridge: University Press.

Chaudhry, A., Wayne, S. J., \& Schalk, R. A (2009). Sensemaking model of employee evaluation of psychological contract fulfillment. The Journal of Applied Behavioral Science, 45(4), 498-520.

Cheng, B., Wang, M., Moorman, J., Olaniran, B. A., \& Chen, N.-S. (2012). The effects of organizational learning environment factors on e-learning acceptance. Computers \& Education, 58, 885-899.

Chiaburu, D. S. (2010). The social context of training: Coworker, supervisor, or organizational support? Industrial and commercial training, 42(1), 53-56.

Chiaburu, D. S., \& Marinova, S. V. (2005). What predicts skill transfer? An exploratory study of goal orientation, training self-efficacy and organizational supports. International Journal of Training and Development, 9, 110-123.

Clarke, N. (2002). Job/work environment factors influencing training transfer within a human service agency: Some indicative support for Baldwin and Ford's transfer climate construct. International Journal of Training and Development, 6(3), 146-162.

Colquitt, J. A., LePine, J. A., \& Noe, R. A. (2010). Towards an integrative theory of training motivation: A meta-analytical path analysis of 20 years of research. Journal of Applied Psychology, 85(5), 678-707.

Creswell, J. W. (2007). Qualitative inquiry and research design. Thousand Oaks: Sage Publications.

Devos, C., \& Dumay, X. (2006). Les facteurs qui influencent le transfert: une revue de la littérature. Savoirs, 12, 11-46.

Eisenberger, R. (1986). Perceived organizational support. Journal of Applied Psychology, 71(3), 500-507.

Eisenberger, R. (2002). Perceived organizational support: A review of the literature. Journal of Applied Psychology, 87(4), 698-714.

Eisenberger, R., \& Stinglhamber, F. (2011). Perceived organizational support. Fostering enthusiastic and productive employees. Washington: American Psychological Association.

Eisenberger, R., Armeli, S., Rexwinkel, B., Lynch, P. D., \& Rhoades, L. (2001). Reciprocation of perceived organizational support. Journal of Applied Psychology, 86(1), 42-51. 
Ford, J. K., \& Weissbein, D. A. (1997). Transfer of training: An updated review and analysis. Performance Improvement Quarterly, 10(2), 22-41.

Gegenfurtner, A., Veermans, K., Festner, D., \& Gruber, H. (2009a). Motivation to transfer: An integrative literature review. Human Resource Development Review, 8(3), 403-423.

Gegenfurtner, A., Festner, D., Gallenberg, W., Lehtinen, E., \& Gruber, H. (2009b). Predicting autonomous and controlled motivation to transfer training. International Journal of Training and Development, 13(2), 124-138.

Grossman, R., \& Salas, E. (2011). The transfer of training: What really matters. Training and Development, 15(2), 103-120.

Haccoun, R. R., \& Laroche, R. (1999). Maximiser le transfert des apprentissages en formation: Un guide pour le praticien. Revue Québecquoise de Psychologie, 20(1), 9-22.

Hall, D. T. (2004). The protean career: A quarter-century journey. Journal of Vocational Behavior, 65(1), $1-13$.

Hawley J. D., \& Barnard, J. (2005). Work environment characteristics and implications for training transfer: A case study of the nuclear power industry. Human Resource Development International, 8(1), 65-80.

Higgins, E. T. (1987). A theory relating self and affect. Psychological Review, 94(3), 319-340

Holton, E. F., III (1996). The flawed four-level evaluation model. Human Resource Development Quarterly, 7(1), 5-25.

Holton, E. F., III, Bates, R., \& Ruona, W. E. (2000). Development of a generalized Learning Transfer System Inventory. Human Resource Development Quarterly, 11(4), 333-360.

Hung, H., \& Wong, Y. H. (2007). The relationship between employer endorsement of continuing education and training and work and study performance: A Hong Kong case study. International Journal of Training and Development, 11(4), 295-313.

Kaddouri, M. (2002). Le projet de soi entre assignation et authenticité. Recherche et Formation, 41, 31-47.

Kaddouri, M. (2006). Dynamiques identitaires et rapports à la formation. In J. -M. Barbier, E. Bourgeois, G. de Villers, \& M. Kaddouri (Ed.), Constructions identitaires et mobilisation des sujets en formation (pp. 121-145). Paris: L'Harmattan.

Kaddouri, M. (2011). Motifs identitaires des formes d'engagement en formation. Savoirs, 25, 69-86.

Kirkpatrick, D. (1959). Techniques for evaluating training programs. Journal of the American Society for Training and Development, 13(11), 3-9.

Kontoghiorghes, C. (2002). Predicting motivation to learn and motivation to transfer learning back to the job in a service organization: A new systemic model for training effectiveness. Performance Improvement Quarterly, 15, 114-129.

Koster, F., de Grip, A., \& Fouarge, D. (2011). Does perceived support in employee development affect personnel turnover? The International Journal of Human Resource Management, 22(11), 2403-2418.

Kraimer, M., \& Wayne, S. (2004). An examination of perceived organizational support as a multidimensional construct in the context of an expatriate assignement. Journal of Management, 30, 209-237.

Kraimer, M., Seibert, S., Wayne, S., Liden, R., \& Bravo, J. (2010). Antecendents and outcomes of organizational support for development: The critical role of career opportunities. Journal of Applied Psychology, 96(3), 485-500.

Lancaster, S., Di Milia, L., \& Cameron, R. (2012). Supervisor behaviours that facilitate training transfer. Journal of Workplace Learning, 5(1), 6-22.

Lee, C. H., \& Bruvold, N. T. (2003). Creating value for employees: Investments in employee development. Human Resource Management, 14(6), 981-1000.

Lim, D. H., \& Johnson, S. D. (2002). Trainee perceptions of factors that influnce learning transfer. International Journal of Training and Development, 6(1), 36-48.

Machin, A. M., \& Fogarty, G. J. (2004). Assessing the antecedents of transfer intentions in training context. Training and Development, 8(3), 222-236.

Madera, J., Steele, S., \& Beier, M. (2011). The temporal effect of training utility perceptions on adopting a trained method: The role of perceived organizational support. Human Resource Quarterly, 22(1), 69-86.

Maurer, T., Pierce, H., \& Shore, L. (2002). Perceived beneficiary of employee development activity: A Three-Dimensional Social Exchange Model. Academy of Management Review, 27(3), 432-444.

Montesino, M. U. (2002). A descriptive study of some organizational-behavior dimensions at work in the Dominican Republic: Implications for management development and training. Human Resource Development International, 5(4), 393-410. 
Naquin, S. S., \& Holton, E. F., III (2002). The effects of personality, affectivity, and work commitment on motivation to improve work through learning. Human Resource Development Quarterly, 13(4), 357-376.

Noé, R. A., \& Schmitt, N. (1986). The influence of trainee attitudes on training effectiveness: Test of a model. Personnel Psychology, 39(3), 497-523.

Pajo, K., Coetzer, A., \& Guenole, N. (2010). Formal development opportunities and withdrawal behaviors by employees in small and medium-sized enterprises. Journal of Small Business Management, 48(3), 281-301.

Pattie, M., Benson, G., \& Baruch, Y. (2006). Tuition reimbursement, perceived organizational support, and turnover intention among graduate business school students. Human Resource Development Quarterly, 17(2), 423-442.

Pidd, K. (2004). The impact of workplace support and identity on training transfer: A case study of drug and alcohol safety training in Australia. International Journal of Training and Development, 8(4), 274-288.

Rouiller, J. Z., \& Goldstein, I. L. (1993). The relationship between organizational transfer climate and positive transfer of training. Human Resources Development Quarterly, 4, 377-390.

Scaduto, A., Lindsay, D., \& Chiaburu, D. S. (2008). Leader influences on training effectiveness: Motivation and outcome expectation processes. International Journal of Training and Development, 12(3), $158-170$.

Simosi, M. (2012). Disentangling organizational support construct. Personnel Review, 41(3), 301-320.

Van den Bossche, P., Segers, M., \& Jansen, N. (2010). Transfer of training: The role of feedback in supportive social networks. International Journal of Training and Development, 14(2), 81-94.

Weick, K. E. (1995). Sensemaking in organizations. Thousand Oaks: Sage Publications.

Weick, K. E., Sutcliffe, K. M., \& Obstfeld, D. (2005). Organizing and the Process of Sensemaking. Organization Science, 16(4), 409-421. 